Arch. Vet. Scienc., 4(1):45-49, 1999

Printed in Brazil

\title{
CITOTOXICIDADE "IN VITRO" DE CLOROFENOXIACETATO COM CÉLULAS HEPÁTICAS DE Metynnis roosevelti (PISCES, CHARACIDAE) EM CULTIVO
}

\author{
LÍGIA MARIA SALVO; ROSÁRIA REGINA TESONI DE BARROS RICHARTZ; \\ MARA ELIZA GAZINO JOINEAU; MARIA IVETTE CARBONI MALUCELLI; METRY BACILA
}

Laboratório de Piscicultura, Curso de Pós-Graduação em Ciências Veterinárias - Universidade Federal do Paraná (FPR) Rua Dos Funcionários 1540 - CEP 800.35.050 Paraná-Brasil.

\begin{abstract}
In vitro" citotoxicity of 2,4-D + MCPA (2,4-dichlorophenoxyacetic acid + 4-chloro-2methylphenoxyacetic acid) tests were carried out with primary cultures of hepatic cells from Metynnis roosevelti (Pisces, Teleostei, Characidae). To establish the $\mathrm{CL}_{50}$ values, two different methods were used: the measurement of cell viability by means of "neutral red" and by the direct microscopic observation of the defective cells by means of an IM inverted microscope. The average $\mathrm{CL}_{50}$ value of the hepatic cells in primary cultures exposed to the chlorophenoxyacetates used, has been established between 0.0265 and $0.0312 \mathrm{~g} / \mathrm{ml}$.
\end{abstract}

RESUMO - Células hepáticas de Metynnis roosevelti obtidas de cultivo celular primário foram submetidas a ensaios de citotoxicidade "in vitro" com os princípios ativos 2,4-D+MCPA (ácido 2,4 diclorofenoxiacético+ácido 4-cloro-2-metilfenoxiacético). Para determinação da $\mathrm{CL}_{50}$ foram utilizados dois métodos: um por meio da viabilidade celular com "vermelho neutro" e outro através da observação direta das células afetadas com microscópio invertido IM. A CL $\mathrm{CL}_{50}$ média das céluas hepáticas de Metynnis roosevelti em

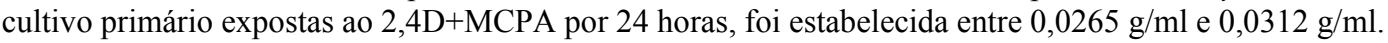

\section{Introdução}

Estudos de citotoxicidade in vitro utilizando culturas de células de peixes, tem sido desenvolvidos para diferentes aplicações (BOLS et al., 1985), inclusive para identificar os efeitos de agressores químicos que causam impacto no meio ambiente (CASTAÑO et al., 1995; CHENG et al., 1993; BABICH et al., 1987; KOCAN et al., 1985).

Em 1968, PILCHER et al. apud WOLF e QUIMBY (1969), realizaram os primeiros estudos comparando o crescimento com a atividade glicolítica de células de salmonídeos em cultivo. Se bem que tenha sido um trabalho preliminar, conseguiram esses autores detectar diferenças na atividade glicolítica de células em cultivo de peixes em comparação com a de outras espécies animais. As células em cultivo de peixe, mantém seu nível normal de atividade enzimática melhor do que as de mamíferos. Em consequência, possibilitam a determinação da toxicidade de substâncias químicas, com maior sensibilidade, rapidez e menores custos (AHNE, 1985; SEGNER et al., 1994).

Testes de toxicidade com animais são freqüentemente utilizados na investigação dos efeitos da contaminação do meio ambiente. Alguns testes são limitados pelo número de animais que podem ser economica e convenientemente estudados, por problemas em obter animais de linhagens puras e em perfeito estado físiológico, e dificuldade de extrapolar resultados de uma espécie para outra. Um meio encontrado para superar essas dificuldades foi a utilização do cultivo de células que permite a análise de uma grande quantidade de amostras e determina com maior especificidade a atividade do agente tóxico nas células de um único organismo (KOCAN et al., 1984; SAITO e SHIGEOKA, 1994).

A sensibilidade aguda dos animais a diferentes compostos tóxicos varia muito de espécie para espécie e mesmo quando uma espécie adequada é escolhida como bioindicadora, suas respostas agudas ou crônicas a diferentes compostos tóxicos variam de acordo com outros fatores, como a resistência individual, a predisposição genética do organismo, além das condições físico-químicas do ambiente e da ocorrência ou não de relacionamentos sinérgicos entre os compostos químicos no local (HAWKINS, 1987; HAKANSSON et al., 1991). Consequentemente, a utilização apropriada de células isoladas em meio de cultivo, possibilita separar as várias alterações físicas e químicas que interagem com os organismos prejudicando as reações. Por meio disso, permite o estudo de ações específicas no interior das células sem a interferência dos efeitos de outros sistemas (DIPPLE e BIGGER, 1983).

$\mathrm{Na}$ década de sessenta, os pesquisadores já utilizavam testes de citotoxicidade in vitro com células em cultivo de peixes para detectar os efeitos causados por agentes tóxicos em organismos aquáticos. Em 1965, PICKERING e VIGOR apud RACHLIN e PERLMUTER, 1968, determinaram a toxicidade de metais pesados na embriogênese de salmonídeos; RACHLIN e PERLMUTER, 1968, verificaram redução na replicação celular de uma cultura de células de peixes da família dos salmonídeos, expostas ao zinco por 96 horas.

Recentemente, com o aumento na utilização de 
agentes tóxicos de ordem natural ou antropogênica e conseqüente degradação ambiental (KOCAN et al., 1984), são inúmeros os trabalhos realizados que utilizam células de peixes em cultivo como instrumento de estudo para avaliação da contaminação do ambiente aquático (PARKINSON e AGIUS, 1988; BABICH e BORENFREUND 1987a; SAITO et al., 1991).

O presente trabalho (SALVO, 1997) teve como objetivo, realizar testes de citotoxicidade "in vitro" com células hepáticas de Metynnis roosevelti em cultivo primário, utilizando os princípios ativos 2,4D+MCPA. nas seguintes concentrações: 0,0275 $\mathrm{g} / \mathrm{ml} ; \quad 0,00275 \mathrm{~g} / \mathrm{ml}$ e $0,000275 \mathrm{~g} / \mathrm{ml}$. A concentração letal média do herbicida, ficou em torno de $0,0275 \mathrm{~g} / \mathrm{ml}$, para as células hepáticas de Metynnis roosevelti em cultivo primário.

\section{Metodologia}

Com a obtenção das células hepáticas em monocamada de Metynnis roosevelti, semeadas em microplacas de poliestireno Falcon na densidade de $3 \times 10^{4}$ células por $\mathrm{ml}$ com meio F10-199 modificado pela adição de L-glutamina $2 \mathrm{mM}$ (FLOURIOT et al., 1993; CHENG et al., 1993; KOCAL et al., 1987), insulina $10 \mu \mathrm{g} / \mathrm{ml}$ (HAYASHI e OOSHIRO,1986; HIGHTOWER e RENFRO, 1988; WATANABE et al., 1986; LIPSKY et al., 1986) e $50 \mu \mathrm{g} / \mathrm{ml}$ de fibronectina (Gibco BRL, Bovine Plasma Fibronectin) (CHENG et al., 1993; HIRATA, et al., 1993) foram realizados os testes de citotoxicidade in vitro de acordo com a metodologia de BABICH e BORENFREUND, (1987 a.,b,c,d,e,f). Células hepáticas de peixes da família Characidae foram incubadas em câmara de $\mathrm{CO}_{2}$ a $5 \%$ e temperatura constante de $30^{\circ} \mathrm{C}$ por 24 horas. Posteriormente, o meio foi trocado e as células, por um período de 24 horas, colocadas em contato com o agente a ser testado (2,4-D+MCPA) em várias diluições $\left(10^{-1}\right.$, $10^{-2}, 10^{-3}, 10^{-4}, 10^{-5}, 10^{-6}$ ) para determinação do $\mathrm{CL}_{50}$; (Tabela I). Após esse período, o meio com o agente a ser testado foi removido e substituido pelo meio F10-199 contendo $50 \mu \mathrm{g} / \mathrm{ml}$ de "vermelho neutro". As microplacas, foram então incubadas por 3 horas para permitir que o corante lisossomas das células viáveis, que não foram prejudicadas pelo agente a ser testado, no caso o herbicida diclorofenoxiacético (2,4-D+MCPA). Posteriormente, o meio com "vermelho neutro" foi removido, e as células rapidamente enxaguadas com fixador (formaldeído $4 \% \mathrm{e} \mathrm{CaCl}_{2} \quad 1 \%$ ) adicionandose, então, a cada poço $0,2 \mathrm{ml}$ da mistura de ácido acético $1 \%$ com etanol $50 \%$ para a extração do corante. Após 20 minutos à temperatura ambiente e uma rápida agitação, a placa foi transferida para o espectrofotômetro ATC 340 Labtene com filtro de $540 \mathrm{~nm}$ para medir a absorbância. Após a adição de "vermelho neutro", a população celular submetida ao estresse pelo agente a ser testado, foi observada em microscópio invertido IM.

Tabela 1. Número total de semeaduras nas microplacas.

\begin{tabular}{c|c|c|c|c|c|c}
\hline \multicolumn{7}{c}{ Diluições do 2,4 -D+MCPA em g/ml } \\
\hline Controle & $10^{-1}$ & $10^{-2}$ & $10^{-3}$ & $10^{-4}$ & $10^{-5}$ & $10^{-6}$ \\
\hline 480 & 288 & 288 & 288 & 288 & 288 & 288 \\
\hline
\end{tabular}

\section{ÍNDICE DE TOXICIDADE DO HERBICIDA 2,4- D+MCPA}

Para determinação da diluição do herbicida diclorofenoxiacético, e o estudo de seu efeito tóxico $\left(\mathrm{CL}_{50}\right)$, foi utilizada a fórmula de Spearman Karber (BERQUÓ et al., 1981):

$\sum \mathrm{T}_{50}=\mathrm{t}^{*}+\Delta \mathrm{t}$, onde

$\mathrm{t}^{*}=$ maior diluição do herbicida diclorofenoxiacético que causou efeito tóxico em oito (100\%) dos pocinhos da microplaca; $\Delta \mathrm{t}=$ número de pocinhos afetados (onde a monocamada celular foi parcial ou totalmente destruída), em t ${ }^{*}$ e em diluições maiores dividido por oito menos $4 / 8(50 \%)$;

$$
\begin{aligned}
& \Delta \mathrm{t}=(8+0) / 8-4 / 8=4 / 8 \\
& \Delta \mathrm{t}=0,5 \\
& \Sigma \mathrm{T}_{50}=\mathrm{t}^{*}+\Delta \mathrm{t} \\
& \Sigma \mathrm{T}_{50}=10^{-1,5}
\end{aligned}
$$

Calculando-se o anti-logarítmo, têm-se a diluição do herbicida que quando utilizada causará efeito tóxico em $50 \%$ dos pocinhos.

\section{Resultados e Discussão}

ÍNDICE DE TOXICIDADE DO HERBICIDA 2,4D+MCPA. Com o herbicida 2,4-D+MCPA, adicionado às células hepáticas em cultivo nas diferentes concentrações, após 24 horas foi feita a contagem dos pocinhos afetados (Tabela 1) através do microscópio invertido IM. Esses resultados estão expressos nos cálculos abaixo:

Cálculo da Diluição do Herbicida diclorofenoxiacético (2,4-D+MCPA)

Determinação da $\mathrm{CL}_{50}$ :

$\Sigma \mathrm{T}_{50}=\mathrm{t}^{*}+\Delta \mathrm{t}$

$\mathrm{t}^{*}=1.0$ 


$$
\begin{array}{ll}
\Delta \mathrm{t}=(6+0) / 6-3 / 6=3 / 6 & \text { anti-log } 1,5=1: 31,62 \\
\Delta \mathrm{t}=0,5 & \text { Índice de Toxicidade do } 2,4-\mathrm{D}+\mathrm{MCPA} \\
\Sigma \mathrm{T}_{50}=\mathrm{t}^{*}+\Delta \mathrm{t} & 50 \% \\
\Sigma \mathrm{T}_{50}=10^{-1,5} & \text { IT } 50 \%=0,03162 \mathrm{~g} / \mathrm{ml}
\end{array}
$$

\begin{tabular}{|c|c|c|c|c|}
\hline \multirow{2}{*}{\multicolumn{2}{|c|}{ Controle }} & \multicolumn{3}{|c|}{ Concentrações do 2,4 D + MCPA } \\
\hline & & $0,0275 \mathrm{~g} / \mathrm{ml}$ & $0,00275 \mathrm{~g} / \mathrm{ml}$ & $0,000275 \mathrm{~g} / \mathrm{m}$ \\
\hline & 0,782 & 0,374 & 0,442 & 0,584 \\
\hline & 0,748 & 0,371 & 0,444 & 0,509 \\
\hline & 0,783 & 0,381 & 0,427 & 0,557 \\
\hline & 0,664 & 0,382 & 0,493 & 0,534 \\
\hline & 0,729 & 0,321 & 0,464 & 0,533 \\
\hline & 0,679 & 0,373 & 0,462 & 0,509 \\
\hline & 0,604 & 0,364 & 0,497 & 0,553 \\
\hline & 0,721 & 0,388 & 0,409 & 0,591 \\
\hline & 0,685 & 0,337 & 0,476 & 0,594 \\
\hline & 0,674 & 0,364 & 0,423 & 0,517 \\
\hline & 0,784 & 0,382 & 0,427 & 0,541 \\
\hline & 0,631 & 0,396 & 0,487 & 0,584 \\
\hline Média & 0,707 & 0,36941667 & 0,45425 & 0,5755 \\
\hline
\end{tabular}

Tabela 2. Valores de absorbância (nm) obtidos em teste de citotoxicidade in vitro de células hepáticas de M. roosevelti em cultivo expostas a diferentes concentrações do herbicida 2,4 D+MCPA.

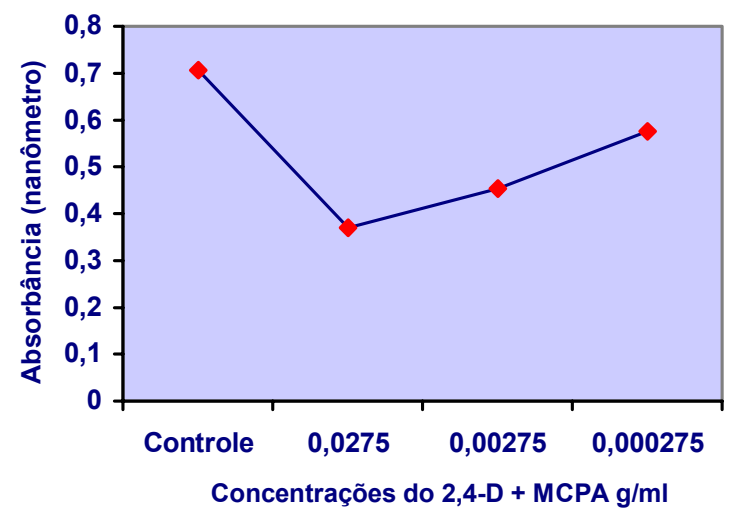

Fig. 1. Representação gráfica dos valores médios de absorbância obtidas em teste de citotoxicidade in vitro de células hepáticas de M. roosevelti em cultivo expostas a diferentes concentrações do herbicida 2,4 - D+MCPA.

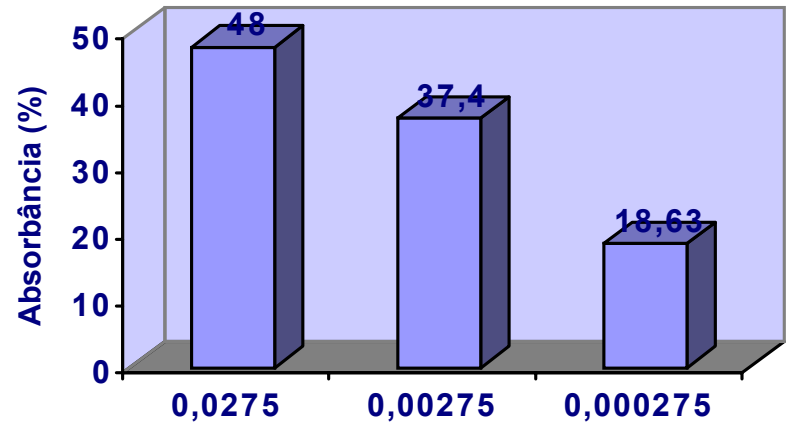

Concentrações do 2,4-D + MCPA g/ml

Fig. 2. Representação gráfica da percentagem de absorbância obtida em teste de citotoxicidade in vitro de células hepáticas de $M$. roosevelti em cultivo expostas a diferentes concentrações do herbicida 2,4 - D+MCPA. 
Os valores obtidos na tabela 2 , demonstram que em células afetadas, a absorbância do "vermelho neutro" diminui em comparação com a das células controle. Os lisossomas das células viáveis irão absorver o "vermelho neutro", portanto com a adição do etanol $50 \%$ mais ácido acético para a extração do corante, a solução se tornará mais corada, sendo proporcional ao número de células viáveis, ou seja, que não foram submetidas aos efeitos do 2,4-D+MCPA (Fig. 1 e 2).

Apesar de ambos os testes de citotoxicidade, terem se complementado, recomenda-se, que para o teste da absorbância, segundo a metodologia descrita anteriormente, sejam utilizadas células de linhagem já estabelecida, pois foi verificado uma pequena variância nas leituras de absorbância dos pocinhos da microplaca. A hipótese é de que o cultivo celular primário não apresenta uma uniformidade na densidade da monocamada, como as células de linhagem já estabelecida, além disso, a atividade enzimática dessas células, por não serem genotipicamente iguais, varia muito de lote para lote.

\section{REFERÊNCIAS BIBLIOGRÁFICAS}

AHNE, W. Studies on the fish tissue cultures for toxicity tests in order to reduce and replace the fish tests. $Z b l$. Bakt. Hyg. I Abt. Orig. B. 180:480-504, 1985.

BABICH, H.; BORENFREUND, E. Fathead minnow FHM cells for use in in vitro Cytotoxicity assays of aquatic pollutants. Ecotoxicology and Environmental Safety. 14, p. 78-87, 1987a.

BABICH, H. e BORENFREUND, E. In vitro cytotoxicity of organic polluants to bluegill Sunfish (BF-2) Cells. Environmental Research. 42, p. 229-237, 1987b.

BABICH, H.; BORENFREUND, E. Aquatic pollutants tested in vitro with early passage fish cells. ATLA. $15,116-122,1987 \mathrm{c}$.

BABICH, H.; BORENFREUND, E. Cytotoxicity and genotoxicity assays with cultured fish cells: a Review. Toxic. in Vitro. 5(1):91-100, 1991d.

BABICH, H.; BORENFREUND, E. Fathead minnow FHM cells for use in in vitro cytotoxicity assays of aquatic pollutants. Ecotoxicol. and Environ. Safety. 14, 78-87, 1987e.

BABICH, H.; BORENFREUND, E. In vitro cytotoxicity of organic pollutants to bluegill sunfish (BF-2) Cells. Environ. Research. 42, 229 - 237, $1987 f$.

BABICH, H.; PALACE, M.R.; STERN, A. Oxidative stress in fish cells: in vitro studies. Arch. Environ. Contam. Toxicol. 24, 173-178, 1987.

BERQUÓ, E.S.; PACHECO DE SOUZA, J.M.; GOTLIEB, S.L.D.; Bioestátistica 1 ed. rev São Paulo, Editora Pedagógica e Universitária Ltda, p. 350, 1981.

BOLS, N.C.; BOLISKA, S.; DIXON, D.G.; HUDSON, P.V.; KAISER, K.L.E. The Use of Cell cultures as na indicator of contaminant toxicity to fish. Aquatic Toxicol. 6:147-1155, 1985.

CASTAÑO, A.; VEGA, M.M.; TARAZONA, J.V. Acute toxicity of selected metals and phenols on RTG - 2 and CHSE - 214 fish cell lines. Bull. Environ. Contam. Toxicol. 55, 222-229, 1995.
CHENG, L.L.; BOWSER, P.R.; SPITSBERGEN, M. Develpment of cell cultures derived from lake trout liver and kidney in a hormone-supplemented, serumreduced medium. Journ. of Aquatic Animal Health. 5, 119-126, 1993.

DIPPLE, A.; BIGGER, C.A.H. Metabolic properties of "in vitro" systems. In: cellular systems for toxicity testing. Ann. N.Y. Acad. Sci. 407:26-33, 1983.

FLOURIOT, G.; VAILLANT, C.; SALBERT, G.; PELISSERO, C.; GUIRAUD, J.M.; VALOTAIRE, Y. Monolayer and aggregate cultures of rainbow trout hepatocytes: long-term and stable liver-specific expression in aggregates. J. of Cell Science. 105, 407-416, 1993.

HAKANSSON, H.; SUNDIN, P.; ANDERSSON, T.; BRUNSTROM, L.; DENCKER, L.; ENGWALL, M.; EWALD, G.; GILEK, M.; HOLM, G.; HONKASALO, S.; IDESTAM-ALMIQUIST, J.; JONSSON, P.; KAUTSKY, N.; LUNDBERG, G.; LUND-KVERNHEIM, A.; MARTINSEN, K.; NORRGREN, L.; PERSONEN, M.; RUNDGREN, M.; STALBERG, M.; TARKPEA, M.; WESEN, C. In vivo and in vitro toxicity of fractionated fish lipids, with particular regard to their content of chlorinated organic Compounds. Pharmacol. \& Toxicol. 69, 459-471, 1991.

HAWKINS, W.E. Carcinogenetic tests with small fish species. Aquat. Toxicol. 11:00-00, 1987.

HAYASHI S.; OOSHIRO, Z. Primary culture of the Eel hepathocytes in the serum-free medium. Bulletin of the Japanese Society of Scientific Fisheries. 52(9):1641-1651, 1986.

HIGHTOWER, L.E. \& RENFRO, J.L.. Recent applications of fish cell culture to biomedical research. The Journ. of Exp. Zool., 248, 290 - 302, 1988.

HIRATA, K.; YOSHIDA, Y.; SHIRAMATSU, K.; FREEMAN, A.E.; HAYASAKA, H. Effects of laminin, fibronectin and type IV collagen on liver cell cultures. Expl. Cell Biol. 51, p 121-129, 1993.

KOCAL, T.; QUINN, B.A.; SMITH, J.R.; FERGUSON, H.W.; HAYES, M.A. Use of trout serum to prepare primary attached monolayer cultures of hepatocytes from rainbow trout (Salmo gairdneri) In Vitro Cellular \& Developmental Biology. 24(4):304-308, 1987.

KOCAN, R.M.; SABO, K.M.; LANDOLT, M.L. Cytotoxicity/genotoxicity: the application of cell culture techniques to the measurement of marine sediment pollution. Aquatic Toxicol. 6, 165-177, 1984.

LIPSKY, M.M.; SHERIDAN, T.R.; BENNETT, R.O.; MAY, E.B. Comparison of trout hepatocyte culture on different substrates. In Vitro Cellular \& Developmental Biology. 22(6):360-362, Jun, 1986.

PARKINSON, C.; AGIUS, C. Acute toxicity of DDT to Tilapia (Oreochromis spirulus Gunther) in vivo and in vitro. ATLA. 15, $298-302,1988$.

RACHLIN, J.W.; PERLMUTTER, A. Fish cells in culture for study of aquatic toxicants. Water Research Perganon Press. 2:409-414, 1968.

SAITO, H.; SHIGEOKA, T. Comparative cytotoxicity of clorophenols to cultured fish cells. Environ. Toxicology and Chem. 13, 10:1649-1650, 1994. 
SAITO, H.; SUDO, M.; SHIGEOKA, T. \& YAMAUCHI, F.. In vitro cytotoxicity of chlorophenols to Goldfish GF - scale (GFS) cells and quantitative structure - activity relationships. Environ. Toxicol. and Chem., 10, 235 - 241, 1991.

SALVO, L.M. Estudo do citotoxicidade "in vitro" de clorofenoxicetatos de células hepáticas de Metynnis roosevelti (PISCES, CHARACIDAE). Tese de mestrado. Curso de Pós Graduação em Ciências Veterinárias, Universidade Federal do Paraná, Curitiba 1997.
SEGNER, H.; LENZ, D.; HANKE, W.; SCHURMANN, G. Citotoxicity of metals toward rainbow trout R1 cell line. Environ. Toxicol. and Water Quality: An International Journ. 9, 273-279, 1994.

WATANABE, T.; NAKANO, M.; ASAKAWA, H.; MORITOMO, T. Cell culture of rainbow trout liver. Nippon Suisan Gakkaishi. 53, 4:537-542, 1986.

WOLF, K.; QUIMBY, M.C. Fish cell and tissue culture. In: Hoar, W.S.; Randall, D.J., eds. Fish Physiology. 3, 253-305, 1969. 